\title{
Assessing the Role of Money versus Interest Rate in Pakistan
}

\author{
ZAFAR HAYAT and MUHAMMAD NADIM HANIF
}

\begin{abstract}
We have empirically examined the role of monetary aggregate(s) vis-à-vis short-term interest rate as monetary policy instruments, and the impact of State Bank of Pakistan's transformation into the latter on their relative effectiveness in terms of inflation in Pakistan. Using indicators of 'persistent changes' in the underlying behaviours of variables of interest, we found that broad money consistently explains inflation in (i) monetary (ii) transitory and (iii) interest rate regimes. Though its role has receded while moving from the transition to the interest rate regime, the interest rate instrument seems to be positively related to inflation, a phenomenon commonly known as price puzzle. In light of these findings, we recommend that the role of money should not be completely de-emphasised.
\end{abstract}

JEL Classification: E31, E52.

Keywords: Monetary Policy Instruments, Price Puzzle, ARDL, Pakistan

\section{INTRODUCTION}

Although the debate about the choice of an appropriate monetary policy instrument is well known, it is far from being settled. The main instruments over which disagreements have persisted are the price, interest rateand quantity of money. ${ }^{1}$ While there is a consensus that both cannot be used simultaneously at the same time to influence the target variables (Turnosky, 1975), studies concluded differently on their relative effectiveness as monetary policy instruments. For example, Sargeant and Wallace (1975) argued that reserve money is a better instrument as compared to the interest rates because the latter suffers from the problem of equilibrium indeterminacy. Similarly, Bhattacharya and Singh (2007) found that money maximises welfare in the presence of real shocks. ${ }^{2}$ Gordon (1979) on the other hand concluded in favour of the superiority of the interest rate over monetary instruments for Canada. Similarly, Atkeson et al. (2007) found that the interest rates have a natural advantage over money instruments.

Zafar Hayat <zafar.hayat@sbp.org.pk> is Senior Economist, IMF, Islamabad. Muhammad Nadim Hanif <nadeem.hanif@sbp.org.pk> is Additional Director, Research Department, State Bank of Pakistan, Karachi.

Authors' Note: The authors are thankful to Ali Choudhary, Muhammad Rehman, Muhammad Jahanzeb Malik, Fayyaz Hussain, Javaid Iqbal and the two referees for their useful comments, discussions and suggestions on an earlier draft of this study.

${ }^{1}$ Atkeson et al. (2007) accounts for exchange rate as one of the instruments in addition to interest rates and money

${ }^{2}$ It may be noted that they also found that in the presence of nominal and relatively small shocks instead of money, interest rate instruments are better. 
Research has also indicated that a combination policy (a certain mix between interest rates and money), as given in Poole (1970) instead may be a better option. He created a theoretical framework for a combination policy. However, his static unified framework only allows answering the underlying question of the relative effectiveness of monetary policy instruments in terms of output rather than the inflation, taming which is the prime objective of most of the central banks today. ${ }^{3}$

Monetary policy practices at the State Bank of Pakistan (SBP), the country's central bank have varied over time (see Hanif, 2014 for details). Historically, money played an important role as a monetary policy instrument. The focus nevertheless has now shifted to the interest rate and currently, an interest rate corridor system is in place effective from August 2009 (Hussain, 2009; Khan, 2010 and Hanif, 2014). Whether this transition of the SBP from an increased focus on money to the use of interest rate as an instrument of monetary policy has been effective; and should the former be completely deemphasised vis-à-vis the latter are crucial questions yet to find research-based answers. It is also important to ascertain if the transformation of Pakistan's monetary policy's focus from targeting monetary aggregates to the active use of short-term interest rates has any bearing on their relative effectiveness in terms of inflation over time in the country.

To the best of our knowledge, this is an unexplored research area. In a related attempt, Ali and Ahmad (2014) explored the relative performance of inflation, and price level targeting regimes under alternative monetary policy instruments, and found money as a better performer relative to the interest rate for Pakistan. Their analysis, however, is based on calibrating their model while using parameters from Din and Khan (2011), which used the annual data from 1972-2009. Neither their focus was nor could their study, by construct, observe the evolution of the relative role of money and interest rateespecially in the context of SBP's transition from the former to the latter-which was completed by 2009. It, therefore, did not take into account the full-fledged interest rate regime. Most recently Ahmad et al. (2016) theoretically evaluated the role of money in propagating business cycle fluctuations in Pakistan and found that cash base economy models under money growth rule perform well as compared to the cashless economy models with the Taylor type rule.

In contrast to the aforecited literature, we use; (i) the framework used by Hayat et al. (2016) to extract indicators of persistent changes in the variables of interest to be able to closely observe the most relevant underlying relationships and, (ii) apply the ARDL approach to estimate such relationships.

The results indicate that money remains a consistent performer vis-à-vis interest rate but its role has been receding with an increased focus of the SBP on the interest rate as a monetary policy instrument. Nevertheless, there is evidence of a positive relationship between the interest rate and inflation, which is indicative of the possibility of a price puzzle. Therefore, it may be advisable for the SBP not to completely de-emphasise the use of money as an instrument of monetary policy (vis-à-vis interest rate) as it has been significantly effective in taming inflation in the country.

We organise the structure of the remainder of our paper as follows. Section 2 lays down a methodological framework for the generation of indicators of persistent changes

${ }^{3}$ Woglom (1979) and Benaive and Richard (1983) are among others who have worked along similar lines. 
in variables of interest. Section 3 discusses the testing and estimation strategy, specifies the model, highlights data. Section 4 brings forth the results and discussion while Section 5 examines the soundness of the generated indicators for the analysis and robustness of the results. Section 6 concludes the paper.

\section{METHODOLOGICAL FRAMEWORK}

In order to examine the relative importance of money versus interest rate as monetary policy tools as well as their evolution over time, following Hayat et al (2016), we first generate indicators representing persistent variations in variables of interest and then use them to estimate their long-term relationships through the ARDL approach (see next section). This is important because only a small fraction of variations in monetary policy instruments may tend to relate to a small fraction of variations in target variables (such as inflation and/or real economic growth) given that the central bank may not necessarily exercise full control over the variations in monetary policy variables especially broad money. This postulation, as a starting point, is consistent with Bullard, 1999; Uhlig, 2005 \& Hayat et al. 2016. We derive indicators of persistent variations from (a) growth in broad money, (b) market interest rate, (c) inflation, and (d) the real GDP growth rate in two steps as follows.

In the first step the Hodrick and Prescott (1997) filter-henceforth HP filter-is applied to decompose the observed series $\left(X_{t}\right)$ into its permanent long term path $\left(X l_{t}\right)$ and the transitory fluctuations $\left(X f_{t}\right)$. The $X f_{t}$ are obtained by subtracting the long-term path from the observed time series $X_{t}$ such that $X f_{t}=X_{t}-X l_{t}$. In the second step, we apply the HP filter to $X f_{t}$ to extract its permanent part $\left(X f l_{t}\right)$, which is the indicator of persistent variations in $X_{t}$. One may ask about the justification of the use of the HP filter. First, our choice of this filter is driven by the fact that the filter allows the trend to vary over time and hence the magnitudes of deviations, which may better represent policy responses (variations) in the underlying policy as well as goal variables (Hayat et al. 2016). Second, double HP filter outperforms other detrending and smoothing methods in turning point signal stability, i.e. identifying turning points quickly (Nilsson \& Gyomai, 2011), which reflect structural changes and hence regimes. This feature is important because our purpose is to observe the evolution of money and interest rate instruments across different regimes: (i) monetary (ii) transitory and (iii) interest rate regimes.

For all the four variables - broad money growth, interest rate, inflation and real GDP growth rate-we, therefore, apply the two-step procedure to obtain our desired indicators of persistent variations as follows.

\subsection{Indicator of Persistent Variations in Broad Money Growth}

In the first step, the HP filter is applied to decompose the observed series of growth in $M 2$ (denoted by $\dot{m} 2_{\mathrm{t}}$ ) over time into its long-term growth path $\dot{m} 2 l_{\mathrm{t}}$ and the fluctuations around it $m \dot{2} f_{\mathrm{t}}$, such that:

$$
\dot{m} 2_{\mathrm{t}}=m \dot{2} l_{\mathrm{t}}+m \dot{2} f_{\mathrm{t}} \quad \text { for } t=1, \ldots \ldots, T .
$$

In the second step, the HP filter is applied to $m \dot{2} f_{\mathrm{t}}$ to obtain its long-term trend path, which corresponds to persistent variations, denoted by $m \dot{2} f l_{\mathrm{t}}$ such that: 


$$
\begin{aligned}
& m \dot{2} f_{\mathrm{t}}=m \dot{2} f l_{\mathrm{t}}+m \dot{2} f f_{\mathrm{t}} \quad \text { for } t=1, \ldots \ldots . . T, \\
& \Rightarrow m \dot{2} f l_{\mathrm{t}}=m \dot{2} f_{\mathrm{t}}-m \dot{2} f f_{\mathrm{t}} \quad \text { for } t=1, \ldots \ldots . T .
\end{aligned}
$$

Where $m \dot{2} f l_{\mathrm{t}}$ is the desired series representing persistent variations in broad money growth.

\subsection{Indicator of Persistent Variations in Interest Rate}

Similarly, the HP filter is applied to decompose the interest rate $\left(i_{t}\right)$ over time into its long-term path and the fluctuations around it. In the first step:

$$
i_{\mathrm{t}}=i l_{\mathrm{t}}+i f_{\mathrm{t}} \quad \text { for } t=1, \ldots \ldots . T .
$$

In the second the HP filter is applied again to $i f_{\mathrm{t}}$ to obtain its long-term path of our interest if $l_{\mathrm{t}}$ as follows:

$$
\begin{aligned}
& i f_{\mathrm{t}}=i f l_{\mathrm{t}}+i f f_{\mathrm{t}} \quad \text { for } t=1, \ldots \ldots . T . \\
& \Rightarrow i f l_{\mathrm{t}}=i f_{\mathrm{t}}-i f f_{\mathrm{t}} \quad \text { for } t=1, \ldots \ldots . . T .
\end{aligned}
$$

\subsection{Indicator of Persistent Variations in Inflation}

The two-step strategy of application of HP filter is also employed to generate indicators of inflation and real GDP growth as follows:

$$
\pi_{t}=\pi l_{t}+\pi f_{t} \quad \text { for } t=1, \ldots \ldots . T,
$$

where $\pi_{t}$ is the inflation rate in time $t$. The $\pi l_{t}$ is its long-term path in time $t$ and $\pi f_{t}$ represents the fluctuations around $\pi l_{t}$ over time. In the first step, the HP filter is applied to $\pi_{t}$ to obtain $\pi l_{t}$ and $\pi f_{t}$. In the second step, the HP filter is applied to $\pi f_{t}$ to obtain its long-term path such that:

$$
\begin{aligned}
& \pi f_{t}=\pi f l_{t}+\pi f f_{t} \quad \text { for } t=1, \ldots \ldots . . T . \\
& \Rightarrow \pi f l_{t}=\pi f_{t}-\pi f f_{t} \quad \text { for } t=1, \ldots \ldots . . T .
\end{aligned}
$$

Where, $\pi f l_{t}$ is the desired inflation indicator.

\subsection{Indicator of Persistent Variations in the Real GDP Growth Rate}

Likewise, the strategy of the application of the two-step HP filter is used to obtain the real GDP growth indicator. Firstly, the time series of the growth in real GDP $\left(\dot{y}_{\mathrm{t}}\right)$ is decomposed into its long-term growth path $\dot{y} l_{\mathrm{t}}$ and the fluctuations around it, i.e. $\dot{y} \dot{f}_{\mathrm{t}}$ such that:

$$
\dot{y}_{\mathrm{t}}=\dot{y} l_{\mathrm{t}}+\dot{y} \dot{f}_{\mathrm{t}} \quad \text { for } t=1, \ldots \ldots . T .
$$

Secondly, the HP filter is applied to $y f_{\mathrm{t}}$ to obtain its long-term path as:

$$
\begin{aligned}
& \dot{y} f_{\mathrm{t}}=\dot{y f} l_{\mathrm{t}}+y \dot{f} f_{\mathrm{t}} \quad \text { for } t=1, \ldots \ldots . . \\
& \Rightarrow y \dot{f} l_{\mathrm{t}}=\dot{y} f_{\mathrm{t}}-y \dot{f} f_{\mathrm{t}} \quad \text { for } t=1, \ldots \ldots T .
\end{aligned}
$$

Where, $y f l_{\mathrm{t}}$ is the desired real growth indicator. 


\section{ESTIMATION APPROACH, MODEL SPECIFICATION AND DATA}

We use the autoregressive distributed lag (ARDL) bounds testing and estimation approach to cointegration proposed by Pesaran and Shin (1999) and Pesaran et al. (2001) to obtain long-run parameter estimates. The estimators of the ARDL are super-consistent for long-run coefficients and it performs particularly well in small samples without losing long-run information. The ARDL approach allows the selection of optimal dynamic models. Since Pesaran and Pesaran 1997; Pesaran \& Shin 1999 reported that the SBC is a consistent model selection criterion in small samples and that it selects a relatively more parsimonious model (Enders, 1995), we use the SBC. The ARDL works even in the presence of endogenous regressors irrespective of the order of integration ( 1 or 0 ) of explanatory variables (Pesaran \& Pesaran, 1997; Pesaran \& Shin, 1999).

Operationally, the ARDL is a two-stage procedure. The first stage is to test for the existence of cointegration by computing the $F$-statistic. Since the asymptotic distribution of this $F$-statistic is non-standard, Pesaran et al. (2001) tabulated two sets of appropriate critical values for $\mathrm{I}(0)$ or $\mathrm{I}(1)$, for different numbers of regressors $(k)$ with and without intercept and trend. If the computed $F$-statistic falls outside the band for respective critical values of $\mathrm{I}(0)$ or $\mathrm{I}(1)$, cointegration exists. If it falls within that band then the result of the inference is inconclusive. In the second stage, long-run coefficients are obtained, provided the cointegration is established in the first stage. In general form, the error correction version of our ARDL model may be given as:

$$
\begin{aligned}
& \Delta \pi f l_{t}=\emptyset_{0}+\sum_{i=1}^{p} \emptyset_{i} \Delta \pi f l_{t-i}+\sum_{j=0}^{q 1} \emptyset_{j} \Delta m \dot{2} f l_{t-j}+\sum_{k=0}^{q 2} \emptyset_{k} \Delta i f l_{t-k} \\
& +\sum_{m=0}^{q 3} \emptyset_{m} \Delta \dot{y} f l_{t-m}+\gamma_{0} \pi f l_{t-1}+\gamma_{1} m \dot{2} f l_{t-1}+\gamma_{2} i f l_{t-1}
\end{aligned}
$$

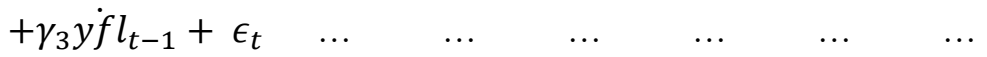

Where $\pi f l, m \dot{2} f l$, $i f l$, and $y \dot{f} l$ are inflation, broad money growth, interest rate and real GDP growth indicators, respectively. The $\Delta$ denotes the first difference operator and $\epsilon$ is the error term.

We use the quarterly data series from Q1-1974 to Q2-2015. The main variables are expressed in terms of a year on year (YoY) change in CPI inflation, real GDP and broad money - which allows us to control possible seasonality - while the call money rate (as a proxy of policy rate) is in levels. The data for broad money growth and call money rate is taken from SBP. Since the policy rate remained constant from 1977 to 1990 (Figure 1), as an alternative, we, therefore, used the call money rate. The call money rate closely mimics the behaviour of the policy rate. ${ }^{4}$ The correlation coefficient between the policy rate and call money rate is 0.95 .

The inflation data has been obtained from the national statistical agency, the Pakistan Bureau of Statistics (PBS). National income accounts are complied by the PBS only on an annual basis; we, therefore, use the quarterly GDP data for Pakistan for the fiscal years 1973-2012 estimated by Hanif et al. (2013). Since they quarterised the data only until 2012, we extended their data set up to 2015 while using the proportions therein, based on the latest available annual data from the PBS for the period 2013-2015. It may be noted that for the entire series to be consistent, we transformed their series from 1974 to 2012 on the new base year, i.e. 2005-2006.

${ }^{4}$ We use the nominal interest rate as the SBP uses nominal rather than real interest rate in its policy messages, and it is the nominal rate that is used/quoted by the banking system in its transactions. 
Fig. 1. Call Money Rate and Policy (Discount) Rate

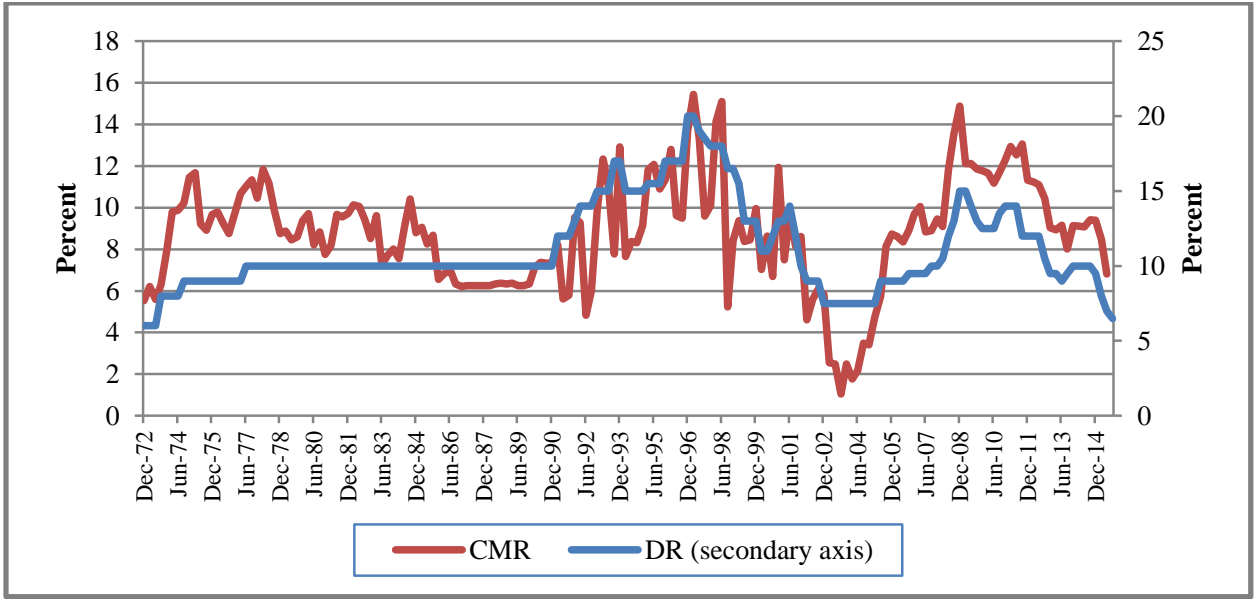

In order to be confident whether our generated 'indicators' represent the behaviours in the respective base variables, and to make sure that it might not have led to a considerable loss of information, we checked their correlations with their respective base variables and cycle series. Figure 2 shows that by and large, double filtering has not led us to lose significant information as exhibited by correlation coefficients with respective base and cycle variables, especially in case of inflation and interest rate indicators. Instead, it seems that rather the noise part has been purged, which may not necessarily be representing policy-induced actions and responses in goal variables as all the shocks may not be treated to be representing informed policy actions or responses (see Hayat et al. 2016). ${ }^{5}$ For example, the correlation between the base variable CPI inflation and its cycle series (CPIT) is 0.71 and that of CPI inflation and our generated indicator is 0.63 (see Figure 2).

Fig. 2. Correlation of the Base Variable with Respective Cycle Series and Generated Indicators

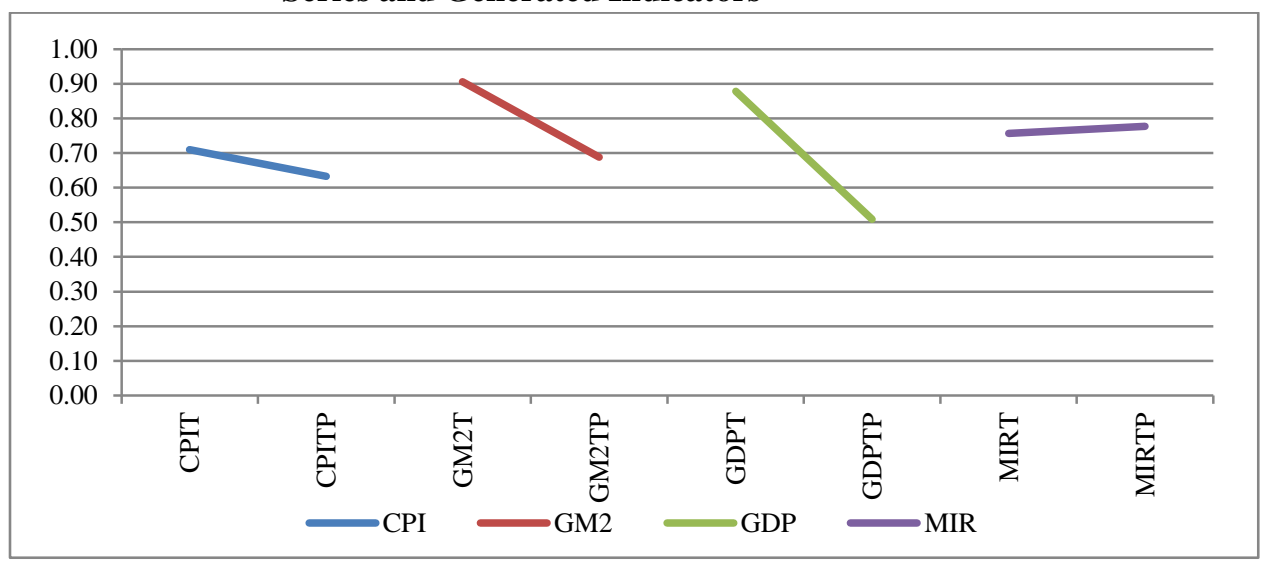

${ }^{5} \mathrm{~A}$ true test to this effect nevertheless would be for the indicators to yield intuitive results as against the base and cycle series (see Section 4 and 5). 


\section{RESULTS}

\subsection{Model Selection, Diagnostic and Cointegration Tests}

Given the lack of theoretical guidance as to what should be the appropriate maximum lag length in a particular situation, we relied on a general-to-specific approach for the imposition of optimal lag lengths. We started with 10 quarters as the maximum lag length in case of the full sample and kept reducing unless we could pick a cointegrating model with no issues of serial correlation, heteroscedasticity, and estimated coefficients' stability. This allowed for up to two and half years, reasonable transmission time for the effects of monetary policy instruments at least in the case of Pakistan (considering past research in this area like Khan, 2008). In the case of sub-samples, any maximum allowable lag length (lower than 10) was tried during the selection process. We used the SBC model selection criterion as it selects the most parsimonious model.

For the model in equation (1), the null hypotheses of the non-existence of a longrun relationship is given by $H_{0}: \gamma_{1}=\gamma_{2}=\gamma_{3}=0$ against the alternative $H_{1}: \gamma_{1} \neq 0$, $\gamma_{2} \neq 0, \gamma_{3} \neq 0$. The $F$-statistics computed for the joint significance of $\gamma_{1}, \gamma_{2}$ and $\gamma_{3}$ for the full (1974-2015) and subsamples (1974-1995, 1995-2009 and 2009-2015) are $10.99,17.51,9.35$ and 162.67 respectively. All these computed statistics exceed the corresponding critical value bands of Pesaran et al. (2001) for unrestricted intercept and no trend at a 1 percent level, leading us to reject the null of the non-existence of a longrun relationship. This implies that the decision to proceed with computing long-run coefficients is conclusive and there is no need to know the cointegration rank (Pesaran \& Pesaran, 1997). The long-run parameter estimates are obtained subsequently.

Although we are mindful of the possibility of endogeneity, we have confidence in our estimates as the ARDL methodology we used works well even in the presence of endogenous regressors irrespective of the order of integration [I(1) or I(0)] of explanatory variables (Pesaran \& Pesaran, 1997; Pesaran \& Shin, 1999). Alternative methodologies to minimise the extent of possible endogeneity are 2SLS and GMM, which, however, require identification of 'instrumental variables'. Generally, it is hard to find 'instrumental variables' for the variables in the equation to be estimated. In those cases, suggestion in the empirical literature is the use of lagged variables. In this study, the way we have developed each indicator, it in itself is like an instrument for the underlying variable. And that the use of the lagged values of these indicators in the ARDL modeling reduces the chances of endogeneity in our estimation.

\subsection{Money Versus Interest Rate-Regime-wise Results}

Since our objective is to assess if the SBP should place an increased emphasis on interest rate compared to the broad money and whether the transformation in the focus of Pakistan's monetary policy from the latter to the former has had any bearing on their relative effectiveness in terms of inflation, we analyse sub-periods that correspond to i) monetary targeting regime (1974-1995), ii) transition period from monetary targeting to interest rates as monetary policy instruments (1995-2009) and iii) an interest rate regime (2009-2015). ${ }^{6}$ Furthermore, as a cross-check, we used the Bai Perron test (1998) for the 
identification of multiple breakpoints and found supporting evidence that breaks occurred in 1995 and 2009 (Appendix 1). Further supporting evidence of these breaks can also be had from the cointegration graph for our full sample model (see the first panel of Appendix 2).

The results indicate that a clear picture cannot be seen when the estimations are carried out for the full sample from 1974 to 2015 as neither money nor interest rate has a significant role in explaining inflation in Pakistan (Table 1, column (a)). This may be because during the entire sample period, the SBP's monetary policy preferences in terms of use of instruments have varied, obscuring the results for the overall sample. This, however, is not the case when we subsequently observe the results for the specific regimes.

Table 1

\begin{tabular}{lcccc}
\multicolumn{5}{c}{ Long-run Estimates } \\
\hline & Mull Sample & Monetary & Transition & Interest Rate \\
& Regime & Period & Regime 2009- \\
Variables & $1974-2015$ & $1974-1995$ & $1995-2009$ & 2015 \\
\hline \multirow{2}{*}{ ifl } & $(\mathrm{a})$ & $(\mathrm{b})$ & $(\mathrm{c})$ & $(\mathrm{d})$ \\
& 0.39 & 0.16 & 1.06 & 0.61 \\
$m \dot{2} f l$ & {$[0.12]$} & {$[0.67]$} & {$[0.00]^{* * *}$} & {$[0.00]^{* * *}$} \\
& 0.08 & 0.95 & 1.26 & 0.60 \\
$y f l$ & {$[0.57]$} & {$[0.02]^{* *}$} & {$[0.00]^{* * *}$} & {$[0.00]^{* * *}$} \\
& -0.81 & -5.93 & -1.37 & -1.70 \\
$a$ & {$[0.09]^{*}$} & {$[0.04]^{* *}$} & {$[0.00]^{* * *}$} & {$[0.00]^{* * *}$} \\
& 0.01 & 0.14 & 0.05 & -0.07 \\
ECT $(-1)$ & {$[0.38]$} & {$[0.01]$} & {$[0.05]$} & {$[0.00]$} \\
ARDL & -0.003 & -0.004 & -0.02 & -0.35 \\
COIN & {$[0.00]^{* * *}$} & {$[0.00]^{* * *}$} & {$[0.00]^{* * *}$} & {$[0.00]^{* * *}$} \\
DW & $(8,3,6,4)$ & $(8,1,5,8)$ & $(5,2,5,0)$ & $(2,0,2,2)$ \\
$R^{2}$ & $1 \%$ & $1 \%$ & $1 \%$ & $1 \%$ \\
\hline & 1.86 & 2.10 & 2.03 & 2.18 \\
& 0.99 & 0.99 & 0.99 & 0.99 \\
\hline
\end{tabular}

This table reports the long-run coefficients and the P-values. The latter are reported in brackets. ARDL shows the order of the lags of the selected models whereas COIN stands for cointegration. ***, ** and * indicate significance at 1 percent, 5 percent and 10 percent level, respectively.

The supply-side effects of real growth seem rather visible, which tend to reduce inflation. This result is consistent with Hayat et al. (2016) which founded an inverse relationship between the real growth and inflation indicators using the annual data from 1961 to 2010. Although the question may remain that whether the real activity indicator used is proxying the supply or demand side of the economy. We advocate the former because the real growth in GDP is used rather than nominal. Furthermore as is visible from column (b) through (d) in Table 2, the magnitude of the effect of the real growth on inflation decreases, which make sense only when real growth represents an increased supply of goods and services - as the average real growth witnessed in the sample period used in columns (b) (c) and (d) are 5.60, 4.47 and 3.41 respectively. 
During the monetary targeting regime, the role of money in explaining inflation is both significant and quantitatively large as against interest rate (Table 1, column (b)). This result is consistent with a range of studies that have found brad money an important determinant of inflation in Pakistan such as Chaudhary \& Ahmad, 1996; Price \& Nasim, 1999; Kemal, 2006; Khan \& Schimmelpfennig, 2006; Serfraz \& Anwar, 2009 \& Hayat et al. 2016. A straightforward policy implication for the SBP from these results is that money plays a significant role in explaining inflation and, therefore, it may be used as an effective monetary policy instrument to tame it. It is, however, interesting to note that interest rate whilst being insignificant during the monetary targeting regime, grew in significance during the transition period to the interest rate regime (Table 1, column (c)).

Under the interest rate regime, both money and interest rate played a significant role in explaining inflation; however, the quantitative effect of the latter is more pronounced in this regime as compared to the transition regime. On the other hand, the quantitative effect of broad money receded vis-à-vis the interest rate instrument during the transition period. These results imply that the shift in focus from monetary aggregates towards interest rate as a monetary policy instrument has had implications both for the relative importance and significance of the two monetary policy instruments.

When taken in isolation, although the interest rate instrument grew in significance during transition and interest rate regimes, it may not effectively guide the monetary policy as it brings forth an important monetary policy issue for the SBP, commonly known in the literature as 'price puzzle', wherein interest rate and inflation are positively related. $^{7}$

The price puzzle issue is non-trivial as it renders the interest rate instrument ineffective [vis-à-vis the broad money instrument in conducting monetary policy], which is the main policy tool currently used by the SBP. We, therefore, suggest that money should not be deemphasised.

\section{SOUNDNESS OF INDICATORS AND ROBUSTNESS CHECK}

To check whether our generated double-filtered indicators have allowed us to obtain intuitively consistent approximations of the underlying phenomena, we did the estimations both using the base data and cycle series. The results obtained using base data (Table 2) - although not as intuitive as the results obtained from our double-filtered indicators - by and large, provide support to our mainstream results as compared to the results obtained by using cycle series (Table 3 ).

All the mainstream models obtained using double-filtered indicators not only fits the data well but also approximate cointegrating relationships as compared to the models that instead uses the variables in base and cycle form. The results obtained by using cycle series are highly inconsistent. They largely depict incorrect signs and do not pick the breaks, thus failing to track the evolution in the relative role of money versus interest rates. On the contrary, the results obtained using the model with generated indicators better identify the breaks in a cointegrating relationship (see Appendix 2).

${ }^{7}$ Javid and Munir (2010) also found similar results. Felipe (2009), Naqvi and Rizvi (2010) also pointed to this issue while examining the suitability of adoption of inflation targeting for Pakistan. 
Table 2

Long-run Estimates Using Base Data

\begin{tabular}{|c|c|c|c|c|}
\hline Variables & $\begin{array}{c}\text { Full Sample } \\
1974-2015 \\
\text { (a) }\end{array}$ & $\begin{array}{c}\text { Monetary } \\
\text { Regime } \\
1974-1995 \\
\text { (b) }\end{array}$ & $\begin{array}{c}\text { Transition } \\
\text { Period } \\
1995-2009 \\
\text { (c) }\end{array}$ & $\begin{array}{c}\text { Interest Rate } \\
\text { Regime 2009- } \\
2015 \\
\text { (d) }\end{array}$ \\
\hline & 0.62 & 0.33 & 1.53 & 1.41 \\
\hline$i_{t}$ & {$[0.01]^{* *}$} & [0.34] & {$[0.00]^{* * *}$} & {$[0.00]^{* * *}$} \\
\hline$m 2_{t}$ & $\begin{array}{c}0.44 \\
{[0.01]^{* *}}\end{array}$ & $\begin{array}{c}0.26 \\
{[0.12]}\end{array}$ & $\begin{array}{c}0.20 \\
{[0.51]}\end{array}$ & $\begin{array}{c}0.24 \\
{[0.46]}\end{array}$ \\
\hline$\dot{y}_{\mathrm{t}}$ & $\begin{array}{c}0.01 \\
{[0.98]}\end{array}$ & $\begin{array}{c}-1.07 \\
{[0.02]^{* *}}\end{array}$ & $\begin{array}{c}1.79 \\
{[0.15]}\end{array}$ & $\begin{array}{l}-0.39 \\
{[0.54]}\end{array}$ \\
\hline$a$ & $\begin{array}{l}-3.71 \\
{[0.25]}\end{array}$ & $\begin{array}{c}8.04 \\
{[0.08]}\end{array}$ & $\begin{array}{r}-16.49 \\
{[0.02]}\end{array}$ & $\begin{array}{l}-7.14 \\
{[0.23]}\end{array}$ \\
\hline $\operatorname{ECT}(-1)$ & $\begin{array}{c}-0.22 \\
{[0.00]^{* * *}}\end{array}$ & $\begin{array}{c}-0.29 \\
{[0.00]^{* * *}}\end{array}$ & $\begin{array}{l}-0.29 \\
{[0.11]}\end{array}$ & $\begin{array}{c}-0.67 \\
{[0.05]^{*}}\end{array}$ \\
\hline ARDL & $(7,0,7,1)$ & $(8,0,3,3)$ & $(7,5,8,5)$ & $(2,0,0,0)$ \\
\hline COIN & $1 \%$ & $2.5 \%$ & Nil & Nil \\
\hline DW & 1.99 & 2.01 & 1.98 & 2.26 \\
\hline$R^{2}$ & 0.90 & 0.86 & 0.98 & 0.83 \\
\hline
\end{tabular}

This table reports the long-run coefficients and the $P$-values. The latter are reported in brackets. Nil means no cointegration. ARDL shows the order of the lags of the selected models whereas COIN stands for cointegration. ***, ** and * indicate significance at 1 percent, 5 percent and 10 percent level, respectively.

Table 3

Long-run Estimates Using Cycle Data

\begin{tabular}{|c|c|c|c|c|}
\hline Variables & $\begin{array}{c}\text { Full Sample } \\
1974-2015 \\
\text { (a) }\end{array}$ & $\begin{array}{l}\text { Monetary } \\
\text { Regime } \\
1974-1995 \\
\text { (b) }\end{array}$ & $\begin{array}{c}\text { Transition } \\
\text { Period } \\
1995-2009 \\
\text { (c) }\end{array}$ & $\begin{array}{l}\text { Interest Rate } \\
\text { Regime 2009- } \\
2015 \\
\text { (d) }\end{array}$ \\
\hline & -0.31 & 0.09 & 0.33 & -0.68 \\
\hline$i f_{t}$ & [0.22] & [0.82] & {$[0.32]$} & [0.49] \\
\hline$m \dot{2} f_{t}$ & $\begin{array}{l}-0.15 \\
{[0.18]}\end{array}$ & $\begin{array}{l}-0.20 \\
{[0.18]}\end{array}$ & $\begin{array}{c}0.23 \\
{[0.35]}\end{array}$ & $\begin{array}{l}-0.29 \\
{[0.46]}\end{array}$ \\
\hline$\dot{y f_{t}}$ & -0.01 & -0.57 & 0.22 & 1.85 \\
\hline$a$ & $\begin{array}{l}{[0.93]} \\
-0.05 \\
{[0.81]}\end{array}$ & $\begin{array}{c}{[0.08]^{\top}} \\
-0.10 \\
{[0.83]}\end{array}$ & $\begin{array}{c}{[0.04]} \\
0.03 \\
{[0.95]}\end{array}$ & $\begin{array}{l}{[0.18]} \\
-0.34 \\
{[0.52]}\end{array}$ \\
\hline$E C T(-1)$ & $\begin{array}{c}-0.46 \\
{[0.00]^{* * *}}\end{array}$ & $\begin{array}{c}-0.34 \\
{[0.00] * * *}\end{array}$ & $\begin{array}{c}-0.28 \\
{[0.04]^{* *}}\end{array}$ & $\begin{array}{c}-0.55 \\
{[0.01]^{* *}}\end{array}$ \\
\hline ARDL & $(8,3,6,1)$ & $(5,0,3,0)$ & $(5,0,0,1)$ & $(2,1,0,1)$ \\
\hline COIN & $1 \%$ & Nil & Nil & Nil \\
\hline DW & 1.98 & 1.95 & 1.70 & 2.30 \\
\hline$R^{2}$ & 0.84 & 0.80 & 0.88 & 0.67 \\
\hline
\end{tabular}

This table reports the long-run coefficients and the $P$-values. The latter are reported in brackets. Nil means nonexistence of a cointegrating relationship. ARDL shows the order of the lags of the selected models whereas 
COIN stands for cointegration. $* * *, * *$ and $*$ indicate significance at 1 percent, 5 percent and 10 percent level, respectively.

As far as the robustness is concerned, our results are largely robust to alternative specifications for almost all the sample sizes. First, we dropped the real growth indicator and estimated the model for all the regimes. Second, we ran the regressions for interest rate and broad money indicators both individually and in combination which led us to conclude in favour of our main findings. ${ }^{8}$ Since we also found evidence of a structural break in 1982-83 (Appendix 1), we controlled for it through dummy variable and reestimated our models (a) and (b) in Table 1 just in case the results turn out to be different than without controlling for the structural break. Our inference from the new results obtained, however, remained unaltered. ${ }^{9}$

\section{CONCLUSION}

Pakistan's monetary policy has evolved over time. The evolution of the relative role of money and interest rate is examined across three distinct phases of monetary policy experience in Pakistan, i.e. regime of targeting monetary aggregates, a period of transition towards interest rate and interest rate regime. A framework was created that allowed the generation of indicators to capture persistent variations in underlying variables. Broad money is found to consistently perform vis-à-vis interest rate throughout the entire spectrum in controlling inflation in the country. Its quantum effect, however, started receding during the transition period and almost equalised the interest rate instrument during the interest rate regime. The role of the interest rate is found to be puzzling as it is positively and significantly related to inflation. The use of the interest rate by the SBP, therefore, may not be effective unless this puzzle is explored and addressed. Since broad money is still effective, its role should not be completely deemphasised.

\section{APPENDIX 1}

Bai-Perron Multiple Break Points Test

\begin{tabular}{lccc}
\hline Breaks & F-Statistic & Critical Value & Break Year(s) \\
\hline $1^{*}$ & 41.8 & 18.26 & 1982 \\
$2^{*}$ & 55.89 & 14.45 & 1983,1991 \\
$3^{*}$ & 56.67 & 12.16 & $1983,1991,2005$ \\
$4^{*}$ & 61.99 & 10.56 & $1983,1989,1995,2006$ \\
$5^{*}$ & 56.68 & 8.71 & $1983,1989,1995,2002,2008$ \\
\hline
\end{tabular}

${ }^{8}$ For brevity purposes, these results however are not reported and may be obtained from the corresponding author if needed.

${ }^{9}$ These results are not reported and may be obtained from corresponding author upon request. 
*denotes significance level at 1 percent. A trimming level of 15 percent was used and the maximum breaks allowed were 5. The critical values are that of Bai and Perron (2003).

APPENDIX 2

Supplementary Material

\section{Graph of Base Variables (GCPI is Inflation, GM2 is Growth in Broad Money, and MIR is Market Interest Rate)}

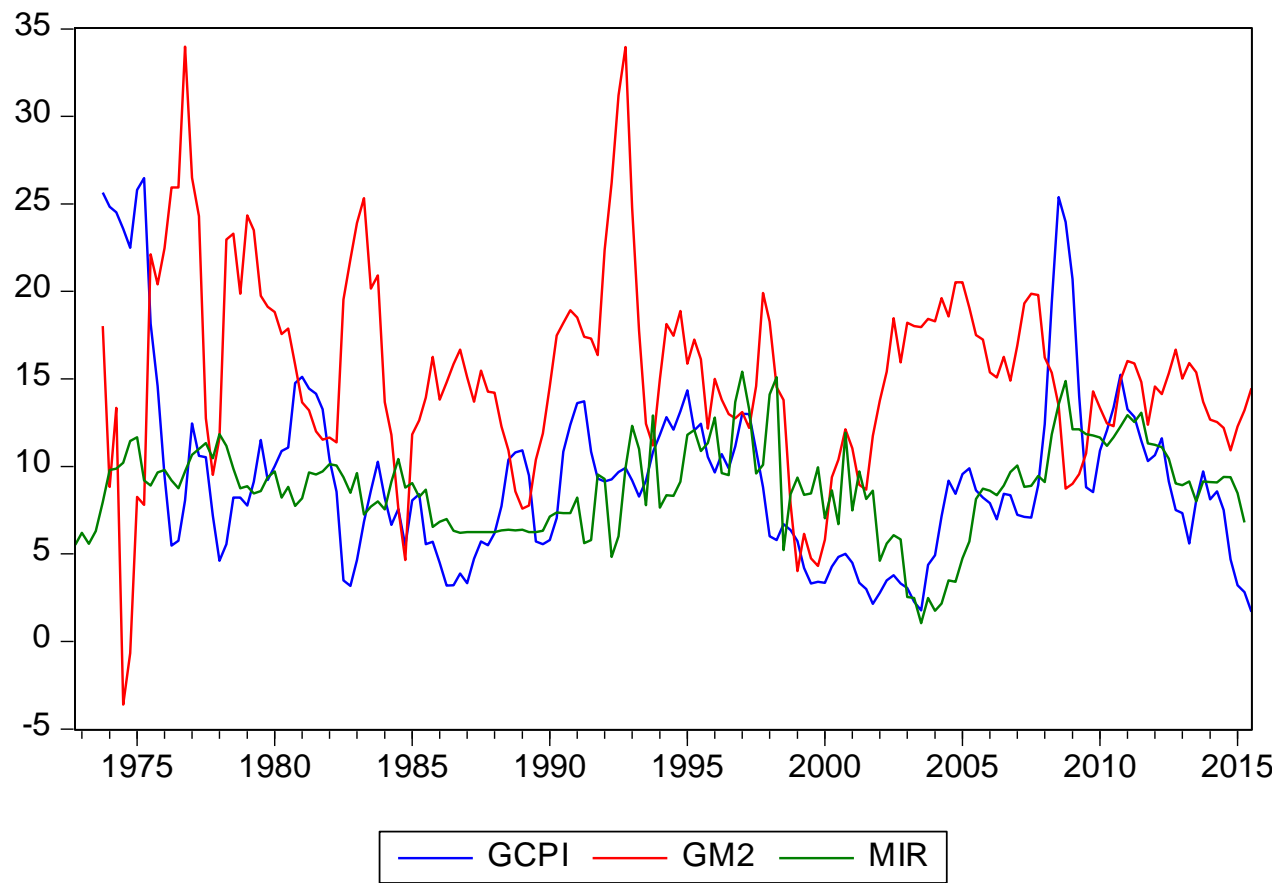

Descriptive Statistics of the Base Variables

\begin{tabular}{lccc}
\hline & GCPI & GM2 & MIR \\
\hline Mean & 9.361266 & 15.30568 & 8.844052 \\
Median & 8.606444 & 15.00142 & 8.936667 \\
Maximum & 26.48080 & 33.99265 & 15.42333 \\
Minimum & 1.780676 & -3.617128 & 1.050000 \\
Std. Dev. & 5.121828 & 5.568757 & 2.607813 \\
Skewness & 1.391459 & 0.245834 & -0.292618 \\
Kurtosis & 5.340424 & 4.615676 & 3.544695 \\
Jarque-Bera & 92.00458 & 19.84619 & 4.447716 \\
Probability & 0.000000 & 0.000049 & 0.108191 \\
Sum & 1563.331 & 2556.049 & 1476.957 \\
Sum Sq. Dev. & 4354.698 & 5147.834 & 1128.914 \\
Observations & 167 & 167 & 167 \\
\hline
\end{tabular}




\section{Unit Root Tests of Base Variables}

Table: Stationarity Properties of The Variables

\begin{tabular}{|c|c|c|c|c|}
\hline \multirow[b]{2}{*}{ Variables } & \multicolumn{2}{|c|}{$A D F$} & \multicolumn{2}{|c|}{$P P$} \\
\hline & $\overline{\text { Level }}$ & First difference & $\overline{\text { Level }}$ & First difference \\
\hline GCPI & {$[0.01]^{* *}$} & & {$[0.01]^{* *}$} & \\
\hline GM2 & {$[0.00]^{* * *}$} & & {$[0.00] * * *$} & \\
\hline MIR & {$[0.06]^{*}$} & {$[0.00]^{* * *}$} & {$[0.00]^{* * *}$} & \\
\hline
\end{tabular}

This table reports the $P$-values of the Augmented Dicky-Fuller $(A D F)$ and the Phillips-Perron $(P P)$ tests in brackets. $* * *, * *$ and $*$ indicate that the series are stationary at the 1 percent, 5 percent and 10 percent level of significance respectively.

\section{REFERENCES}

Ahmad, S., Pasha, F., and Rehman, M. (2016). The role of money in explaining business cycles for a developing economy: The case of Pakistan. (SBP Working Paper Series; WP No. 74).

Ali, H. and Ahmad, E. (2014). Choice of monetary policy instrument under targeting regimes in a simple stochastic macro model. (PIDE Working Papers 2014; 102).

Atkeson, A., Chari V. V., and Kehoe P. J. (2007) On the optimal choice of a monetary policy instrument. (NBER Working Paper Series, Paper No. 13398).

Bai, J. and Perron, P. (1998). Estimating and testing linear models with multiple structural changes. Econometrica, 66(1), 47-78.

Bai, J. and Perron, P. (1998). Computation and analysis of multiple structural change models. Journal of Econometrica, 18, 1-22.

Benavie, A. and Richard T. F. (1983). Combination monetary policies to stabilise price and output under rational expectations. Journal of Money, Credit, and Banking, 18698.

Bhattacharya, J. and Singh R. (2007). Optimal choice of monetary instruments in an economy with real and liquidity shocks. Iowa State University.

Bullard, J. (1999). Testing the long-run neutrality of money: Lessons from the recent research. Federal Reserve Bank of St. Louis Review, 81, 57-77.

Chaudhary, M. A. and Ahmad, N. (1996). Sources and impacts of inflation in Pakistan. Pakistan Economic and Social Review, 34(1), 21-39.

Din, M. U. and Khan, M. A. (2011). A dynamic macroeconometric model of Pakistan's economy. (PIDE Working Papers 2011; 69).

Enders, W. (1995). Applied econometric time series. John Wiley and Sons, Hoboken, New Jersey.

Felipe, J. (2009). Does Pakistan need to adopt inflation targeting? Some questions. SBP Research Bulletin, 5(1), 113-161.

Gordon, S. R. (1979). The choice of monetary policy instruments in Canada. The Canadian Journal of Economics, 12, 15-24.

Hanif, M. N. (2014). Monetary policy experience of Pakistan. (MPRA Paper No. 60855).

Hanif, M. N., Iqbal, J., and Malik, M. J. (2013). Quarterisation of national income accounts of Pakistan. SBP Research Bulletin, 9(1), 1-61. 
Hayat, Z., Balli, F., Obben, J., and Shakur, S. (2016). An empirical assessment ofmonetary discretion: The case of Pakistan. Journal of Policy Modeling. Available at: doi:10.1016/j.jpolmod.2016.05.002

Hodrick, R. J. and Prescott, E. C. (1997). Postwar U.S. business cycles: An empirical investigation. Journal of Money Credit and Baking, 29, 1-16.

Hussain, F. (2009). Framework for SBP's operations in the money market: current practices and recommendations. Internally Circulated Policy Note of Monetary Policy Department, State Bank of Pakistan.

Javaid, M. and Munir, K. (2010). The price puzzle and monetary policy transmission mechanism in Pakistan: structural vector autoregressive approach. The Pakistan Development Review, 49(4), 449-460.

Khan, H. (2010). Overnight repo rate instability: Current practice and solutions. Internally Circulated Policy Note of Monetary Policy Department, State Bank of Pakistan.

Khan, M. H. (2008). Short-run effects of an unanticipated change in monetary policy: Interpreting macroeconomic dynamics in Pakistan. (SBP Working Paper 22).

Khan, M. S. \& Schimmelpfennig, A. (2006). Inflation in Pakistan. The Pakistan Development Review, 45(2), 185-202.

Naqvi, B. and Rizvi, S. K. A. (2010). What does Pakistan have to join inflation targeters club, a royal flush or a seven-deuce offsuit? (MPRA Paper No. 19575).

Nilsson, R. and Gyomai, G. (2011). Cycle extraction: A comparison of the phase-average trend method, the hodrick-prescott and christiano-fitzgerald filters. Available at: https://www.oecd.org/std/leading-indicators/41520591.pdf

Pesaran, M. H. and Shin, Y. (1999). An autoregressive distributed lag modelling approach to cointegration analysis econometrics and economic theory in the 20th century: The ragner frisch centennial symposium (S. Strom ed.). Cambridge: Cambridge University Press.

Pesaran, M. H., Shin, Y., and Smith, R. J. (2001). Bounds Testing Approaches to the Analysis of Level Relationships. Journal of Applied Econometrics, 16, 289-326.

Pesaran, H. M., and Pesaran, B. (1997). Working with microfit 4.0: interactive econometric analysis. Oxford: Oxford University Press.

Poole, W. (1970) Optimal choice of monetary policy instruments in a simple stochastic macro model. Quarterly Journal of Economics, 84, 197-216.

Price, S. \& Nasim, A. (1999). Modelling inflation and the demand for money in Pakistan: cointegration and the causal structure. Economic Modeling, 16, 87-103.

Sargent, T. J. and Wallace N. (1975). Rational Expectations, the Optimal Monetary Instrument and the Optimal Money Supply Rule. Journal of Political Economy, 83, 241-255.

Serfraz, A. \& Anwar, M. (2009). Fiscal imbalances and inflation: A case study of Pakistan. Pakistan Journal of Social Sciences (PJSS), 29(1), 39-50.

Turnovsky, S. J. (1975). Optimal choice of monetary instrument in a linear economic model with stochastic coefficients. Journal of Money, Credit and Banking, 7, 51-80.

Uhlig, H. (2005). What are the effects of monetary policy on output? Results from an agnostic identification procedure. Journal of Monetary Economics, 52, 381-419.

Woglom, G. R. H. (1979). Rational expectations and monetary policy in a simple macroeconomic model. Quarterly Journal of Economics, 93, 91-105. 